\title{
SYNTHESIS AND CHARACTERIZATION OF Co-Zn FERRITE AND \\ MAGNETIC MOMENT MEASUREMENT OF Co-Zn FERRITE BY SOL-GEL ROUTE
}

\author{
M.J.Gothe ${ }^{\circledR}$, A.S.Kakde\$, K.G.Rewatkar\$, P.S.Sawadh* \\ (a) Dept of Physics, N.E.J.C , Wardha 442001,India \\ \$Dept of Physics, Dr Ambedkar College, Nagpur 442010, India \\ *Dept of Physics, B.D.College of Eng. Sewagram, Wardha 442001, India \\ E-mail : madhukargothe@rediffmail.com
}

\begin{abstract}
:
Nanoparticles $\mathrm{Co}_{0.5} \mathrm{Zn}_{0.5} \mathrm{Fe}_{2} \mathrm{O}_{4}$ ( $\mathrm{CZN}$ ) was synthesis by sol-gel auto combustion route. The gel of the solution of CZN fired in a microwave oven for the formation of powder in a nanosize. The X-ray diffraction analysis indicates the formation of single phase ferrite particle in nanosize. Magnetic moment of the above nanosize powder measured by vibrating sample magnetometer (VSM) and exhibits the superparamagnetic (SPM) behavior of the sample. SPM occurs only in nanoparticals which are single domain this is possible only when their diameter is below $60 \mathrm{~nm}$. Other characterization includes TEM, SEM \& EDAX, studied.
\end{abstract}

Keywords: CZN, Superparamagnetic (SPM), XRD, TEM, SEM, EDAX

\section{Introduction:}

Co- $Z n$ ferrites are soft ferrites. That has face centered oxygen atoms and the structure of the ferrite is a spinal Co-Zn ferrite has unpaired electron. In the presence of a magnetic field they posses magnetic moment. Magnetic properties of such a ferrite arise from interactions between metallic ions occupying particular positions relative to the oxygen ion in its spinal crystalline structure. Magnetic domain theory suggests these interactions create magnetic domains which are microscopic magnetized regions within the material. When no magnetizing force is present. The magnetic domains are random and the net flux contribution is zero even though local domains are fully magnetized. When a magnetizing force is present the magnetic domains 
align in the direction of the magnetizing force resulting in a large net flux contribution. Soft ferrites are used mainly in radio and television engineering, telephony and telegraphy would have been impossible in the absence of such a ferrites, but the properties which depends on the materials composition and particle grain sizes. Which is in turn affected by the method of preparation. Ferrite powder can be prepared by different synthesis techniques such as co-precipitation freezing drying and sol-gel. These method can gives ferrites of different forms such as polycrystalline solids and aggregates nanocrystaline of CZN ferrites exhibits superparamagnetic behavior by the study of VSM. SPM has practical applications in the medical field. SPM nanoferrites used in MRI technology, drug delivery etc. Also confirmed the nanosize particals by the study of XRD, TEM, SEM \& EDAX.

\section{Experimental:}

The synthesis of $\mathrm{Co}_{0.5} \mathrm{Zn}_{0.5} \mathrm{Fe}_{2} \mathrm{O}_{4}$ was synthesised by a sol-gel auto combustion method. The raw material used to form the precursors are $\mathrm{Co}\left(\mathrm{NO}_{3}\right)_{2} 6 \mathrm{H}_{2} \mathrm{O}, \mathrm{Zn}\left(\mathrm{NO}_{3}\right)_{2} 6 \mathrm{H}_{2} \mathrm{O}, \mathrm{Fe}\left(\mathrm{NO}_{3}\right)_{3} 9 \mathrm{H}_{2} \mathrm{O} \&$ urea. The appropriate amount of reactant were weighed out in a proportion. All the reactant dissolves in a deionized water. The mixture was heated on $80^{\circ} \mathrm{c}$ till the complete mixed solution transformed in to gel. The gel form of the solution ignited and fired in a microwave oven on 600 watt for $7 \mathrm{~min}$. The gel was burnt out completely forming ash. Finally the ash was grinded with a pestle mortar to obtain the nanosize CZN ferrite powder. To characterize and measure the magnetic moment of the CZN ferrite VSM study was carried out. Further characterization of the CZN ferrite particles involved by XRD, TEM, SEM and EDAX analysis. 


\section{Results and Discussion:}

\section{Auto-combustion behavior of gel of the sample :}

From the experimental observation it was seen that when the gel was fired by auto combusted in microwave oven it burnt completely and to form ash. This method is most useful for the preparation of nanosize particles. Actually sol consist of a liquid of the CZN with colloidal particles which are not dissolve but do not agglomerate or sediment. Agglomerations of small particles are due to Vander Waals forces and a tendency to decrease the total surface energy Vander Waals forces is weak and extended only for a few nanometer. In order to counter the Vander Waals interactions repulsive forces must be established. This forms the nano crystalline nature of CZN ferrite powder.

\section{Particle size and phase analysis:}

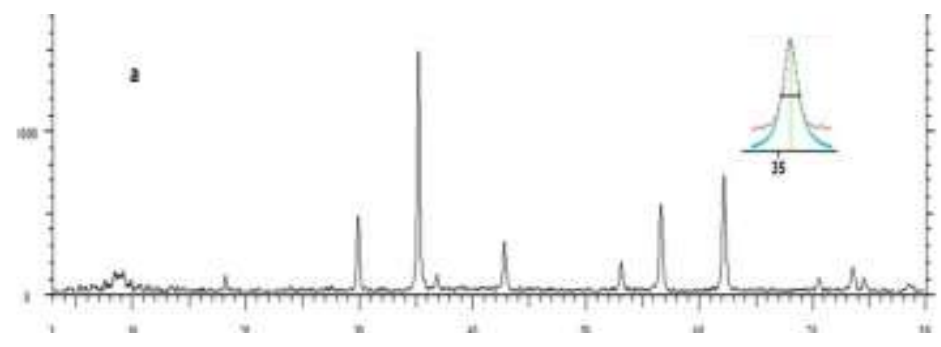

Fig. 1.a) shows XRD of $\mathrm{Co}_{0.5} \mathrm{Zn}_{0.5 \mathrm{Fe}_{2} \mathrm{O}_{4}}$

The powder X-ray diffraction(XRD Bruker AXS D8 Advance, Cu-Ka radiation $\lambda=0.1540 \mathrm{~nm}$ ) pattern of $\mathrm{Co}_{0.5} \mathrm{Zn}_{0.5} \mathrm{Fe}_{2} \mathrm{O}_{4}$ showed a face centre simple cubic spinal structure as shown in fig. 1.The crystalline size (D) of this ferrite was calculated from the (311) plane diffraction peak using the Debye-Sheerer formula, Eq.(1).

$$
\mathrm{D}=0.9 \lambda / \beta \cos \theta
$$

Where, $\lambda$ is the $\mathrm{X}$-ray wavelength $(0.15418 \mathrm{~nm}$ for $\mathrm{Cu}-\mathrm{Ka})$ full width of maximum $\theta$ is the Bragg angle of the (311) plane. The calculated size 
is $37 \mathrm{~nm}$.and its lattice parameter is $8.4539 \AA$. Compare with other method such as co precipitation $(9 \sim 90 \mathrm{~nm})$ and combustion synthesis $(29 \mathrm{~nm})$ sol-gel method yields the ferrite of reasonable particles size. Also we have confirmed size and phase by TEM (TEM Phillips CM-200) analysis could be carried. The average particles size of CNZ nanoferrite is about $58 \mathrm{~nm}$.
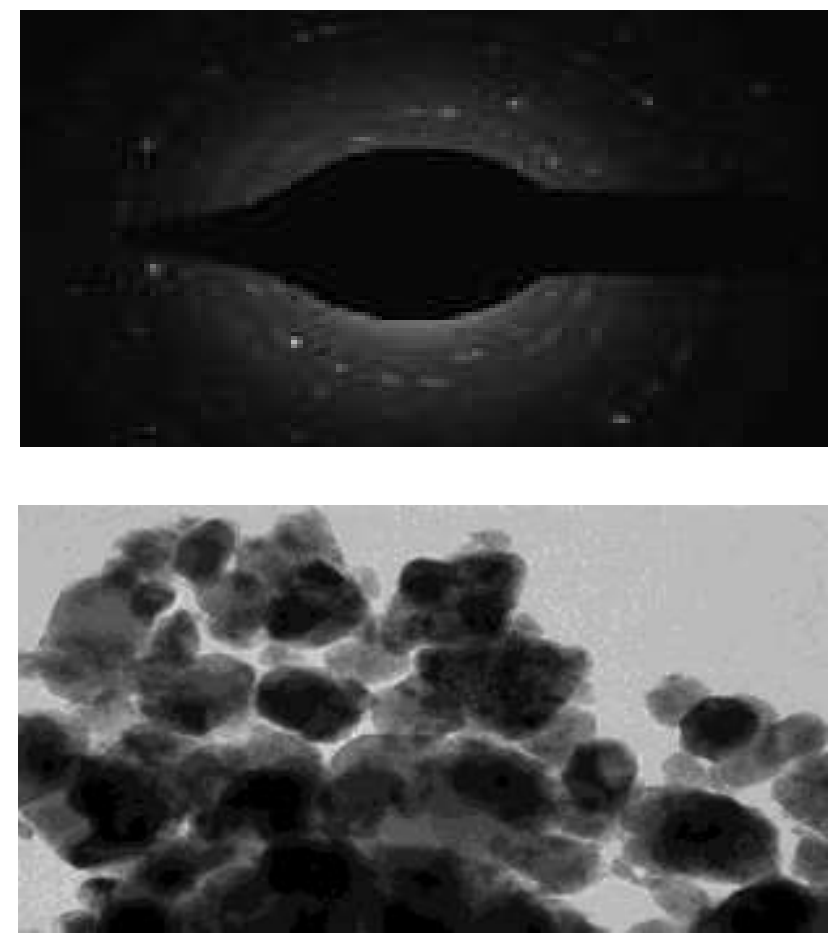

Fig.2.TEM of $\mathrm{Coo}_{2} \mathrm{ZnO}_{0.5 \mathrm{Fe}_{2} \mathrm{O}_{4}}$

In fig. 2. Shows Circular diffraction rings are clearly visible indicating the nanocrystaline nature of the material. Most of the as prepared magnetic nanocrystals have nearly spherical structure in the TEM. Dark regions are representative nanoparticals. Which is in agreement with the SEM findings below. 


\section{Composition analysis:}

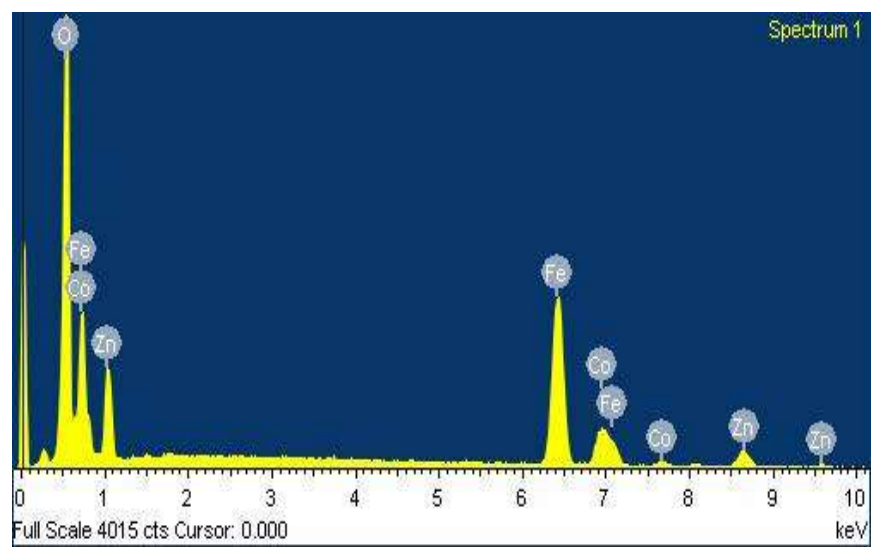

Fig.3.EDAX of $\mathbf{C o}_{0.5} \mathbf{Z n}_{\mathbf{0 . 5}} \mathrm{Fe}_{2} \mathbf{O}_{4}$

By comparing the atomic percentage ratio from the EDAX data. It is confirmed that the nanoferrite form in the molar ratio expected as shown in fig.3.This is because from the result in table.1.

The atomic percentage are $\operatorname{Co}(7.20 \%), \operatorname{Zn}(7.95 \%), \quad \mathrm{Fe}(28.49 \%)$ and $\mathrm{O}(56.36 \%)$. Composition ratio of approximately $1: 1: 4: 8$ that is the ratio composition for $\mathrm{Co}_{0.5} \mathrm{Zn}_{0.5} \mathrm{Fe}_{2} \mathrm{O}_{4}$.

Table.1.

\begin{tabular}{|l|l|l|}
\hline Element & Weight \% & Atomic \% \\
\hline O K & $26.24 \%$ & $56.36 \%$ \\
\hline Fe K & $46.29 \%$ & $28.49 \%$ \\
\hline Co K & $12.35 \%$ & $7.20 \%$ \\
\hline Zn K & $15.13 \%$ & $7.95 \%$ \\
\hline Total & $100.00 \%$ & \\
\hline
\end{tabular}

Morphological and Magnetic Characterization: 


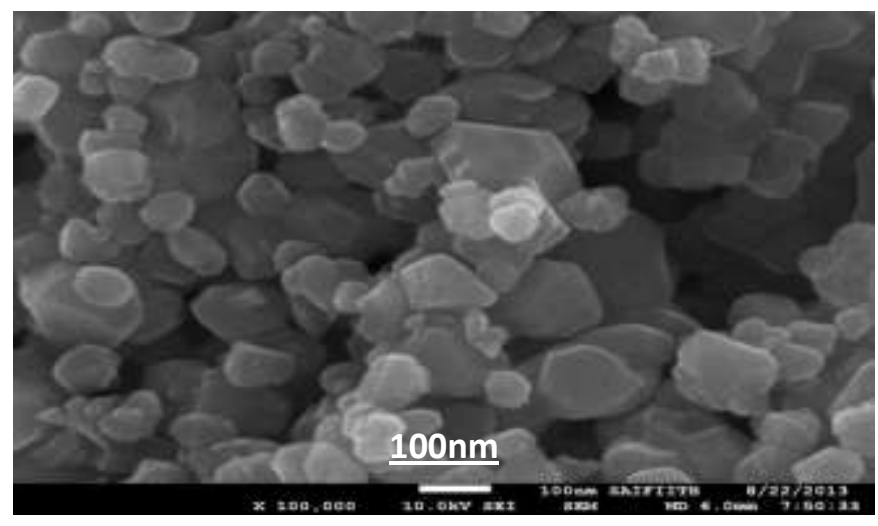

Fig.3.SEM of $\mathrm{Co}_{0.5} \mathrm{Zn}_{0.5} \mathrm{Fe}_{2} \mathrm{O}_{4}$

The morphological studies of the ferrite powder was carried out using SEM (Model JSM-7600F) is a type of electron microscope capable of producing high resolution images of a sample surface[5\&6]. SEM images have a characteristic three dimensional appearance and are useful for judging the surface structure of the ferrite. It is confirmed that the powder were made up of particles with the size in the nanosized range as shown in fig. 3.

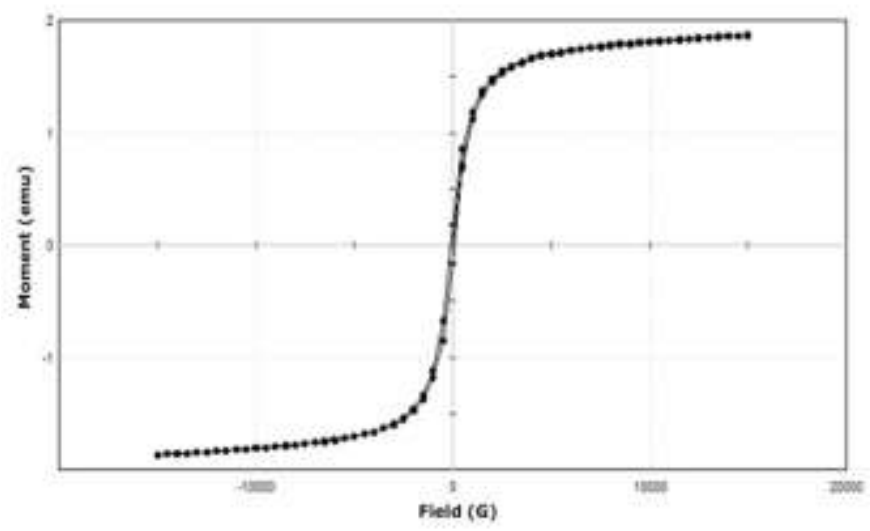

Fig.4. VSM of $\mathrm{Co}_{0.5} \mathrm{Zn}_{0.5} \mathrm{Fe}_{2} \mathrm{O}_{4}$

A curve between magnetic moment and applied field(20KG) at room temperature were measured by VSM (Lakeshwar model 7410) as shown in fig.4. It shows typical superparamagnetic nature with no trace of hysteresis almost immeasurable coactivity ( $102 \mathrm{G})$ and almost zero remanence. It also prominently shows non-attainment of saturation 
magnetization even at 20KG. The non saturation of $\mathrm{M}-\mathrm{H}$ loop and the absence of hysteresis remanence and coercivety at room temperature strongly suggests the presence of superparamagnetic behavior. The lower values of saturation magnetization (1.8688 emu/g ) of nanocrystalline ferrite. Pertaining the fact that the surface effect play vital role in supporting non co linearity of magnetic moment on their surface.In noncrystalline particals consists of ferromagnetically align core-spins and spin glass like surface layers. The disordered behavior in spin from the surface of the nano particals pushes to modify the magnetic properties of these materials specially when the surface /volume ratio is very large.

\section{Conclusions:}

Nano crystalline $\mathrm{Co}_{0.5} \mathrm{Zn}_{0.5} \mathrm{Fe}_{2} \mathrm{O}_{4}$ powders were successfully carried out by sol-gel auto combustion route. Most importantly, we observed that the size and microstructure were in the average range of $58 \mathrm{~nm}$ by the study of SEM, XRD, TEM and the elemental analysis by EDAX showed that the molar ratio of $\mathrm{Me}^{2+} / \mathrm{Fe}^{3+}$ are close to 0.5 concentration. In the study magnetic moment by VSM, CZN ferrite exhibits superparamagnetic characteristics i.e. absence of hysteresis. And the saturation magnetization of ferrite was less than their bulk counterparts and can be discussed.

\section{References:}

Adriana S.A., Josh D.A., and Waldermer A.A.M., (2000). J. Appl. Phy., Vol 87(9), 4352-4357.

Anthony R.W.,(1998). John Wiley and Sons Ltd, Chichester, 553-557.

Costa A.C.F.M., Tirtella E., Morelli M.R., Kiminami R.H.G.A., (2003). J.Magn. Mater. Vol 256, 174-182.

Samuel R.W., (1931), McGraw-Hill, NY, 50-55.

A.S.Barnard, N.A.Marks, S.P.Russo, and I.K.Snook, (2003). Mat. Res. Soc. Symp. Proc. Materials Research Society, pp. I3.4.1 
T. Tyler., V. V. Zhirnov., A.V. Kvit, D. Kang, and J.J. Hren., (2003). “ Appl. Phys. Lett., 8S2, 2904.

Ziolo R.F., Giannelis E.P., Weinstein B.A., O’Horo M.P., Ganguly. B.N., Mehrotra. V., Russel M.W., and Huffman D.R., (1992). Science 257, 219.

Liu C. Zou B.S., Rondinone A.J., and Zhang Z.J., (2000). Am J., Chem.Soc. 122, 219.

Ott G., Wrba J., and Lucke R., (2003). J. Magn. Mater. 254, 535.

Moulin J., Champion Y., Greneche J.M., and Mazaleyrat F., (2003). J. Magn. Mater, 256, 538.

Li F., Liu J.J., Evans D.G., and Duan X., (2004). Chem. Mater.16,1597.

RaJ K., and Moskowitz R., (1990). J. Magn. mater. 85, 233.

YU L., Yang H., Ai X., and Cao Y., (2005). Phys J., Chem. B 109, 1148.

Gubbala s., Nathani H., Koizol K., and Misra R.D., (2004). K.Physica B $348,317$.

Caizer C., (2002). J. Magn. Mater. 251, 304. 